\title{
College Students' Social Problem Analysis and Countermeasures Research
}

\author{
Long Yin, Shuai Ma and Jian Song \\ School of economics, Harbin University of Commerce, Harbin 150028, China
}

Keywords:College student, Social disorder, Measures, Group activities

\begin{abstract}
The contemporary college students in the Internet developed information society, Internet communication has become one of the college students' main social way, face-to-face communication is less and less, even most of the same class are very strange. Many college students have a disgust on interpersonal, in public speaking or interacting with others will make them feel anxiety and fear. They avoid communicating with the people around. This causes damage to the physical and mental health of college students, affecting the sound development of their personality. On the basis of investigating the social situation of college students, this paper analyzes the factors that affect the students' social barriers and puts forward corresponding countermeasures according to the relevant information to help the college students out of the dilemma.
\end{abstract}

\section{The current situation of college students social barriers}

Aristotle once said, people are social animals in the nature, the society is, in fact, prior to the individual existence. Individual who can not live in society, or because they are satisfied, do not need to participate in the social life of the individual, not the mammals, is the gods. We are neither beasts nor gods, inevitably have to contact with society. However, it is difficult for patients with social disorders, and their integration into society is extremely painful. Social Anxiety Disorder, referred to as SAD, will be involuntarily nervous, fear (Especially in the public), so that it is difficult to carry out the normal speech, limb movements are not coordinated. More serious or even afraid to see people, often referred to as social phobia, interpersonal phobia, is a kind of social occasions for a strong fear or anxiety of mental illness. The American scholar study found that the lifetime prevalence of SAD was $13.3 \%$, the third most common psychiatric disorder following severe depression (17.4\%) and alcohol dependence (14.1\%). Epidemiological data, found that only a quarter of people with SAD can return to normal, a third of people with SAD social function significantly affected. The recognition rate of clinical disease, the treatment rate is low and the etiology is not completely clear. People with SAD has characteristic of cognitive mode, such as negative thinking, negative self-evaluation, public awareness and self-attention.

College students with SAD have too much worry and fear about the social scene. They are more alert to the danger and have obvious trait anxiety. Spielberg defines trait anxiety as an acquired behavioral tendency that makes it possible to perceive a number of objectively non-threatening situations as threatening situations, so that their reactions are disproportionate to real dangers. The college students with the social barrier have a significant and lasting fear, fear of their behavior or nervous performance will cause humiliation or embarrassment.

\section{College students' social barriers to the impact of factors}

Through the investigation and analysis, we found that the main factors that affect college students' social barriers are divided into four aspects: physiological factors, psychological factors, family factors, social factors.

Physiological factors. (1)Gender differences: Foreign survey results show that the prevalence rate of male was higher than female. Trait theory is that males tend to define success as the external standard, such as gain prestige or get others to recognition of their achievements, while women are more inclined to internal standards, such as whether to finish the original plan, so men than women are 
more likely to produce social disorder.(2)Own defects: Some of the students who have their own defects because of the physical and others do not dare to get along with people around, afraid of being found their own defects. These defects are their forbidden area, so they keep distance with others to ensure that their defects will not be exposed. In the process of contact with others, they will be more profound understanding of their differences with others, most people will take self-protection measures to isolate themselves from the crowd.

Psychological factors self-esteem level. Some college students because of their high level of self-esteem, many others seem unintentionally joke will be their infinite amplification, that they have been ridiculed, hurt self-esteem; other college students are very low self-esteem, Criticism of the public will also be considered in connection with them, linking all negative messages to themselves. These students' self-esteem level is too high or too low, most of the students are difficult to integrate into the surrounding circle, it is difficult to communicate with others, only in their own world increasingly addicted.

Family factors. (1)Family environment. The survey shows that college students in single-parent families are more likely to suffer from social disorder than college students in parental families. Students who grow up in families with violent factors are more likely to suffer from social barriers than college students who grow up in a harmonious environment. The family environment has a huge impact on the soundness of personality. The family environment has laid a foundation for a person's life. The impact of childhood will follow a lifetime and into the pattern of behavior. A large part of College Students' performance in the Society of fear is due by childhood injury or adolescent desire has not been satisfied.(2)The level of family income. The close of the income gap of the family has great influence on the life and the psychological concept of college students. According to the survey, $60 \%$ of the poor college students are very ashamed of their poverty status. $22.5 \%$ of the poor college students do not want to let others know their own situation. Poverty has had a tremendous impact on the interpersonal relationship of nearly half of the poor college students.

Social factors. (1)Network and other modern means of communication. Psychologists have pointed out that college students' social skills are basically the equivalent of a seven-year-old child level. Increasingly developed in the network today, many college students devoted a lot of time and energy in the network society, little in reality communication, so that students have obstacles in reality to communicate with the outside world. The reality of social and the ability of social networking form a strong gap so that they have a psychological exclusion of social interaction. It is difficult for them to open social communication circle. (2)Impact of ideas- the contradiction between the utilitarian nature of modern social interaction and traditional beliefs. Human nature caused by congenital. In social life, human own interests and their own needs throughout the entire growth process. Social psychologists have suggested that human beings will have private desires from the age of 3 to death. The interpersonal communication had become a utilitarian interpersonal tool. Of course, people also have social attributes. When the social development to a certain stage, the natural attributes of people will rely on the human body and spirit. But this is not a voluntary change of social development and human's last ditch. In the communication, most people are for their own interests and positions as a starting point close to the people who want to deal with him, from which to obtain certain benefits to meet their own desires. For just entering college students, they are not used to the relatively high school period is the utilitarian strong communication mode. The contradiction between utilitarianism and the traditional belief of modern society has become increasingly prominent.(3)Examination-oriented education. At present, China's education is taking the exam oriented. Brush all the time in learning, problem and the reference appendix with the surrounding classmates communicate less and less time. In the eyes of Chinese parents determine whether a child good, only the performance good and bad to measure. This will only lead to students learning ability, but lack of interpersonal interaction. 


\section{Countermeasures for college students' social barriers}

According to the visual P300 and questionnaire survey to determine the level of social barriers to college students. Related researches show that SAD P300 patients and healthy persons in different. Kim reported SAD patients with visual P300 amplitude decreased. Sachs compared with healthy controls, SAD patients' visual P300 amplitude was decreased and the latency prolonged. Through visual P300 and the use of the questionnaire, we can clear the social disorder group of college students, which targeted on college students' social disorder to provide corresponding countermeasures.

Change the cognitive method, treat yourself and others objectively. When we were young, we thought we were different. After growing up we only understand that we are just one of the ordinary people. Correctly understand yourself and understand your ability level is an important step for college students to overcome social barriers.

Change the surrounding environment, ease the anxiety in a peaceful environment. A sound, wind, water etc. "sound of nature" can make the nervous, irritable mood to calm down, improve the anxious mood. Through physical contact with the landscape, the fusion of spirit and the environment of euphoria. First of all, let college students in a natural scenery, so that they relax. Then, use the stage creating life scenes to show the psychological form of the stage. Through this change in the form of the surrounding environment help college students' social barriers to overcome the fear of public places.

Group activities. The last century since 80s, SAD cognitive behavioral therapy was developed. The results of treatment proved to be a good effect. Group activities are based on cognitive behavioral therapy, providing opportunities to test actual behavior and try new behaviors. The collective provides the individual with a mirror of their own. College students' social barriers can be from the collective feel that they need to overcome the exchange of ideas. In the course of the study, ten people were chosen as group groups. First of all, through personal interviews, to understand the subjective intention of individual members of this theme issue and group activities fit and individual seeking change strength. Then, some informed who participate in the activities of groups of people about the group's activities, including the activities of the content, process. Finally, the group of organizations conducts group activities once a month. Use the relevant scale to measure the differences in the performance of the group members at the time of the group activity and at the end of the day. Get the relevant treatment according to the different members of the situation, through the data statistics and analysis.

Building a public platform for We Chat to provide online counseling services for college students with social disorder. It is very difficult for students with social barriers to college students to communicate with a counselor or a professional teacher. They do not want to expose their obstacles in front of the others, the establishment of online consulting platform can be a good solution to this problem. Let college students in the status of the virtual consultation, increase their psychological security. And draw on each person's social barriers to put forward targeted solutions. According to the four factors that affect the social barriers of college students, take them into the collective countermeasures. Let the social disorder patients to enhance communication skills, overcome social sense of fear. As a member of "90", we have a "Beat Generation" in the name of growth, but this is not the final positioning of 90 . College students should shoulder their own responsibility to a healthy and positive attitude to meet the challenge. In "self-cultivation, regulating the family, country and the world" as the criterion, contribute for the country.

\section{Acknowledgment}

This work is supported by.Innovative Entrepreneurship Training Program for College Students: A Study on Social Barriers of College Students (201610240009). 


\section{References}

[1] Leary M R, Davidson JRT, Hughes DL·a1. The epidem iology of social phobial findings from the duke epidem iological catchm ent area study. Psychol Med. Vol. 23 (1993) p. 709-718.

[2] Sachs G, Anderer P, M argreiter N, et a1. P300 event-related potentials and cognitive function in social phobia. Psychiatry Res, Vol. 131 (2004) p. 249-261.

[3] Huabo Wu. Neuropsychological mechanism of oxytocin regulating social disorder. Health Research. Vol 34 (2014) p. 655-658

[4] Jianmin Zhang. A Study on the Realistic Social Obstacles of College Students in the Network Information Age. Education and Teaching Forum. Vol. 31 (2014) p. 179-181.

[5] Sigmund Freud. Self and me. Shanghai Translation Publishing House. 2015 